\title{
Belo Monte: a visibilidade internacional e nacional da Usina Hidrelétrica nos principais jornais do continente americano, europeu e asiático
}

Renata da Cruz Paes

Universidade do Estado do Pará, Belém, Pará, Brasil

Priscila Sanjuan de Medeiros Sarmento

Universidade do Estado do Pará, Belém, Pará, Brasil

Altem Nascimento Pontes

Universidade do Estado do Pará, Belém, Pará, Brasil

\section{Resumo}

Os jornais ainda são as únicas fontes de informação sobre o meio ambiente. Diante desse fato e do grande impacto da construção da Usina Hidrelétrica de Belo Monte, o objetivo do estudo foi realizar um levantamento das matérias jornalísticas sobre Belo Monte entre 2005 e 2017. Os dados foram coletados em sites de jornais de maior circulação nos continentes Americano, Europeu e Asiático. Analisou-se qualitativamente e quantitativamente o conteúdo de 1.188 matérias, de acordo com a proposta de Bardin (2011). O auge da divulgação ocorreu com o leilão da concessão da Usina e com a espetacularização de celebridades que vieram à Amazônia lutar contra Belo Monte. Percebe-se a visão histórica internacional sobre a Amazônia, assim como a ideia de uma Amazônia de propriedade mundial.

\section{Palavras-chave}

Enquadramento. Análise de conteúdo. Jornalismo. Amazônia. Belo Monte.

\section{Introdução}

A região amazônica apresenta, além de uma floresta tropical exuberante, uma das maiores bacias hidrográficas do mundo, vasta planície fluvial e a maior reserva de biodiversidade e de recursos minerais do planeta (FERREIRA; SALATI, 2005). Essas particularidades saltam aos olhos nacionais e estrangeiros. Prova disso é que, em um país como o Brasil, tardiamente industrializado, são comuns os planos de crescimento econômico baseados na implantação de grandes obras de infraestrutura, responsáveis por intensos impactos ambientais e sociais (MORETTO et al., 2012). Para Mendes (2014, p. 333), a Amazônia está no centro do interesse mundial, e alerta: "antes de mais nada, é território que - para além da vida vegetal e animal - abriga a vida de 25 milhões de brasileiros, entre eles minorias étnicas e povos cuja vida está condicionada aos contextos desse território". No passado, 
a Amazônia chegou a estocar índios escravos, foi fonte de lucro por meio da exploração das drogas do sertão e, mais recentemente, é responsável por gerar energia elétrica para grandes projetos nacionais e, até mesmo, para outros países (LOUREIRO, 2002).

Na década de 1970, a crise do petróleo no mercado internacional reduziu o suprimento de combustível para o Brasil, o que fez instalar-se uma crise energética (LIMA et al., 2015). Logo, abriu-se espaço para o governo brasileiro planejar inúmeras barragens (BERMANN, 2012). Se a América do Sul é pródiga para a "indústria barrageira" (SEVA FILHO, 2015), pode-se então dizer que a Amazônia é o berço das barragens. Segundo o atual Plano Decenal de Energia, de 2011 a 2020, dos 39 projetos hidrelétricos planejados, 18 estão localizadas na região amazônica (EMPRESA DE PESQUISA ENERGÉTICA, 2011).

Para Mendes (2014), é inegável que a produção de energia elétrica gerada por barragens tem contribuído para o crescimento e manutenção das atividades humanas, porém permanece inquestionável que esse tipo de produção energética degrada os ambientes naturais e impacta tanto a biodiversidade local e regional, quanto a manutenção dos povos locais (FEARNSIDE, 2011). Junk e Melo (1990) pontuam os impactos da construção de hidrelétricas na Amazônia e citam como principais problemas a translocação da população; a perda de solos, espécies de plantas e animais, de monumentos naturais e históricos, e de recursos madeireiros; as modificações da geografia hidráulica; as mudanças florísticas e faunísticas, além dos impactos na pesca e na aquicultura.

Dentre as barragens planejadas na década de 70, está o Complexo Hidrelétrico de Belo Monte, que foi, por muitos anos, obra prioritária do Governo Federal para o desenvolvimento do setor energético brasileiro (COSTA et al., 2017). Hoje, Belo Monte representa, a terceira maior barragem do mundo, atrás apenas de Três Gargantas, na China, e de Itaipu, no Brasil/Paraguai (MACIEL; KHAN, 2017).

Desde o anúncio da sua criação, a Usina Hidrelétrica (UHE) Belo Monte está em debate na comunidade nacional e internacional haja vista o tamanho do impacto e da importância desse projeto não só para o Brasil, mas para o meio ambiente como um todo (sANTos et al., 2012). Segundo Costa e colaboradores (2017), Belo Monte foi parar nos jornais internacionais a partir da exposição dos problemas ambientais da construção, na Universidade da Flórida, em Miami, Estados Unidos, quando o líder Kaiapó Paulinho Paiakan, Kube-IKaiapó e o etnobiólogo Darrel Posey, do Museu Paraense Emilio Goeldi, expressaram indignação diante da construção do projeto. 
Eles externaram que "financiar um projeto de hidrelétricas no Xingu inundaria 7 milhões de hectares e desalojaria 13 grupos indígenas. Apesar de serem diretamente atingidos, os índios não tinham sido consultados" (XINGU vivo, s.d.).

É por meio da imprensa que a população acompanha o que se passa perto ou longe da própria visão, investiga o que é oculto ou tramado (BARBOSA, 1990). Para Fonseca (2004, p. 115), "a maioria das pessoas depende dos jornais como única fonte de informação sobre o meio ambiente". Diante desss fatos e do grande impacto da construção da UHE de Belo Monte, no meio ambiente e na sociedade, surgiu o interesse em quantificar as matérias jornalísticas divulgadas sobre essa UHE e responder a seguinte questão: quão extensa é a atenção da mídia para este fato e como se desenvolveu? Esse questionamento leva-nos ao objetivo do presente artigo: fazer um levantamento da divulgação de notícias e reportagens sobre a UHE de Belo Monte, publicadas nos jornais nacionais e internacionais, no período de 2005 a 2017.

\section{Metodologia}

Para identificar o número de matérias jornalísticas e quais os eventos no histórico da UHE de Belo Monte que mais se propagaram pela imprensa nacional e internacional, realizou-se um levantamento bibliográfico das matérias jornalísticas, no período de 2005 a 2017, em sites nacionais e internacionais. Ferreira (2002) reforça que investigações bibliográficas conseguem responder quais aspectos e dimensões são destacados e privilegiados conforme as épocas e lugares.

O período para análise não foi escolhido de forma aleatória. Após 17 anos de lutas dos povos indígenas junto ao governo para barrar a implantação da UHE de Belo Monte, em 2005, o Congresso Nacional aprovou em tempo recorde, 15 dias, o processo de licenciamento da hidrelétrica (BRASIL, 2005). $\mathrm{O}$ ano de 2017 marca o início desta pesquisa e da coleta de dados.

Os dados foram coletados em sites jornalísticos de jornais nacionais e internacionais nos continentes americano, europeu e asiático. Para a escolha dos países, foram priorizados os mais populosos, de ligação histórica com o Brasil ou aqueles em que a imprensa tem alcançado o público brasileiro. A escolha dos jornais baseou-se na circulação e na reputação nacional e internacional. Como referência, utilizou-se a pesquisa mais recente realizada pela Associação Nacional de Jornais (ANJ), que lista os 100 jornais de maior circulação no mundo (ANJ, 2011). Baseados em pesquisas e auditorias de mídia internacionais, Zago e Bastos (2013) fizeram um levantamento dos jornais europeus mais 
influentes, o que também serviu de base para a escolha dos jornais da pesquisa.

A pesquisa foi realizada por meio da Análise de Conteúdo (AC), a qual, de acordo com Bardin (2011, p. 48), é como

[...]um conjunto de técnicas das comunicações, visando a obter, por procedimentos sistemáticos e objetivos de descrição do conteúdo das mensagens, indicadores (quantitativos ou não) que permitam a inferência de conhecimentos relativos às condições de recepção/produção (variáveis inferidas).

Foram analisados 24 jornais conforme apresentado no Quadro 1.

Após a seleção dos jornais, fez-se um levantamento das notícias e reportagens nos sites de cada veículo. A amostragem do estudo foi delimitada a partir do ícone de busca dos sites, para que a própria página do jornal fizesse o apanhado geral de matérias a partir das palavras-chave "Hidrelétrica Belo Monte", com adequações para o idioma nativo dos sites internacionais. Optou-se pelo material jornalístico online devido à facilidade que a internet proporciona ao acesso a informações produzidas em todo o mundo (ZAGO; BASTOS, 2013).

Após o levantamento, as notícias foram classificadas em primárias e secundárias.
Sendo primárias todas aquelas em que Belo Monte recebeu destaque no título, a Hidrelétrica foi citada no lead (primeiro parágrafo da matéria jornalística) ou em toda matéria. Para a condição secundária, o estabeleceu-se como critério que as matérias, mesmo não tratando especificamente da UHE de Belo Monte, abordassem discussões sobre hidrelétricas, meio ambiente, geração de energia, corrupção, economia, sociedade, citando Belo Monte em algum momento do texto. Essa classificação foi necessária para diferenciar a relevância da UHE de Belo Monte nas matérias jornalísticas.

\section{Resultados e Discussão - levantamento das matérias jornalísticas}

De 2005 a 2017 foram elencadas 1.188 matérias jornalísticas sobre a UHE de Belo Monte. Destas, 245 são internacionais e 943, nacionais. Das internacionais, 8 são reportagens e 237 são notícias, sendo 143 primárias e 102 secundárias. Das nacionais, 13 são reportagens e 930 são notícias, sendo 580 primárias e 363 secundárias (Figura 1). Confirmou-se, assim, que a UHE de Belo Monte está tanto na mídia nacional quanto na internacional.

De acordo com a Figura 1, do total da amostra contabilizada, $79,4 \%$ são nacionais e $20,6 \%$ internacionais. O jornalismo nacional produziu quase quatro vezes mais conteúdo sobre a UHE de Belo Monte em comparação 
com o internacional. As categorias "notícias jornalísticas secundárias nacionais" chegam nacionais", "reportagens nacionais", "matérias a ser de duas a cinco vezes maiores que os conjornalísticas primárias nacionais" e "matérias teúdos nas mesmas categorias internacionais.

Quadro 1: Jornais selecionados para a coleta de dados com as respectivas homepages

\begin{tabular}{|c|c|c|}
\hline Continente & Países & Jornais \\
\hline \multirow{2}{*}{ América do Norte } & \multirow{2}{*}{ Estados Unidos } & The New York Times \\
\hline & & The Wall Street Journal \\
\hline \multirow{6}{*}{ América do Sul } & \multirow{2}{*}{ Argentina } & Clarín \\
\hline & & La Nación \\
\hline & \multirow{2}{*}{ Brasil } & Folha de São Paulo \\
\hline & & O Globo \\
\hline & \multirow{2}{*}{ Colômbia } & El Espectador \\
\hline & & El Tiempo \\
\hline \multirow{10}{*}{ Europa } & \multirow{2}{*}{ Alemanha } & Die Zeit \\
\hline & & Süddeutsche Zeitung \\
\hline & \multirow{2}{*}{ Espanha } & El Mundo \\
\hline & & El País \\
\hline & \multirow{2}{*}{ França } & Le Figaro \\
\hline & & Le Monde \\
\hline & \multirow{2}{*}{ Portugal } & Diário de Notícias \\
\hline & & Jornal de Notícias \\
\hline & \multirow{2}{*}{ Reino Unido } & The Guardian \\
\hline & & The Sunday Times \\
\hline \multirow{6}{*}{ Ásia } & \multirow{2}{*}{ China } & Pleople's Daily \\
\hline & & Yangtse Evening New's \\
\hline & \multirow{2}{*}{ Coreia do Sul } & The Dong a Ilbo \\
\hline & & The Joogang Ilbo \\
\hline & \multirow{2}{*}{ Índia } & The Hindu \\
\hline & & The Times of India \\
\hline
\end{tabular}

Fonte: Autores, 2018. 
Figura 1: Proporção das matérias jornalísticas, notícias e reportagens, primárias e secundárias, internacionais e nacionais sobre a UHE de Belo Monte no período de 2005 a 2017.

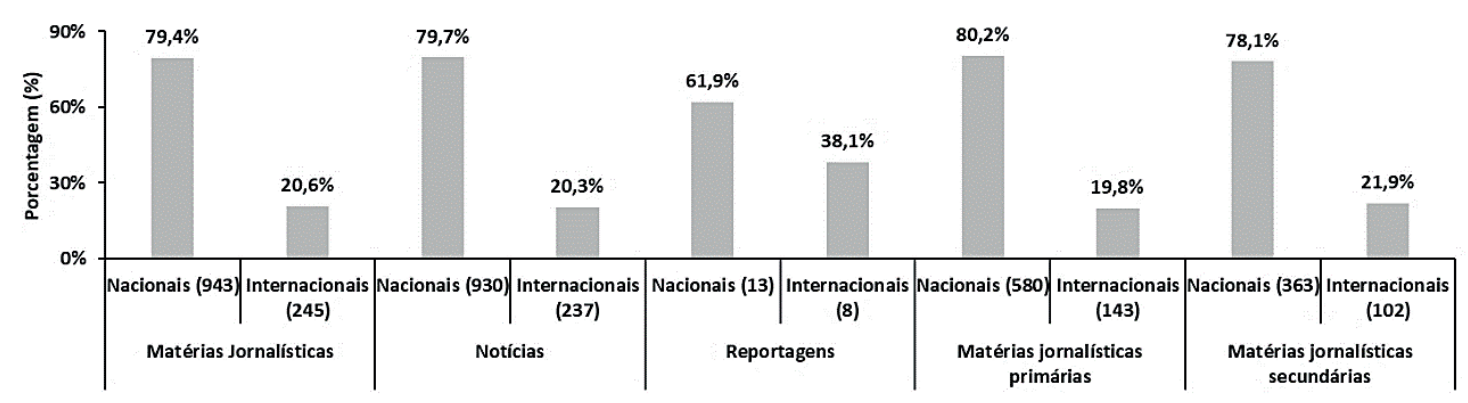

Fonte: Pesquisa de campo.

Esse resultado era esperado, visto que os jornais brasileiros - Folha de São Paulo e O Globo são tidos como os de maior circulação e acesso no Brasil (ANJ, 2011). Logo, as redações tendem a produzir conteúdo que atenda à necessidade do público do próprio país. Em pesquisa sobre comunicação hiperlocal, Magnoni e Miranda (2016) ressaltam que materiais jornalísticos locais ganham destaque diante da globalização, da evolução tecnológica e de uma tendência à homogeneização das identidades. "Há um movimento praticamente involuntário, que instiga as pessoas a reforçarem as suas identidades de origem, a utilizar os localismos como âncoras que lhes possibilitam entrar no movimento global, conviver com diversos valores e cosmovisões" (p. 95). Para os autores (2016, p. 181), “O jornalismo local praticado nos ambientes digitais fornece um importante referencial de sustentação das identidades culturais locais e pode colaborar com a participação cidadã".

\section{Notícias e reportagens}

Das matérias jornalísticas internacionais (245), 96,7\% são notícias (237), e 3,3\% são reportagens (8). O número de matérias jornalísticas internacionais primárias (143) equivale a 58,4\% do total de matérias internacionais (245). Ou seja, em mais da metade das vezes a imprensa internacional reportou a UHE de Belo Monte como tema principal dos conteúdos. Acredita-se que o número superior de notícias em relação ao de reportagens está ligado às "transformações históricas e tecnológicas primordiais" (AGUIAR; RODRIGUES, 2017, p. 302).

Segundo Neveu (2010), o jornalista não vai mais para o campo produzir grandes reportagens, ouvir pessoalmente as fontes, observar os detalhes do ambiente que retratará. Kischinhevsky (2009) reforça que, em nome da produtividade, os jornalistas têm sido meros reprodutores de informação. "Raramente 
o repórter web sai para a rua em busca de um fato. O fato vem até pela própria internet" (FERRARI, 2014, p. 58).

O jornalista que corre atrás de informações tem dado lugar ao profissional que atua somente dentro das redações. Essa mudança de postura foi observada pelos autores Adghirni (2005) e Neveu (2010); este último (2006) chama "jornalismo sentado" (journalisme assis), o praticado pelo repórter que, na cadeira da redação, apenas reproduz as notícias, e "jornalismo em pé" (journalisme debout), aquele que se faz no contato direto com as fontes, por meio das grandes reportagens.

Segundo Silva (2008), as próprias empresas desestimulam a prática da reportagem, o que restringe a apuração ao âmbito da redação. Moretzsohn (2014) reforça que as notícias instantâneas do jornalismo online incentivam a velocidade na apuração e rapidez pela publicação. Em março de 2014, o mesmo autor pesquisou a rotina no jornal O Globo após a adaptação para a edição online e observou "a aceleração no ritmo de trabalho, acúmulo de funções e exaustão ao fim do dia" (MORETZSOHN, 2014, p. 60).

Outro ponto que deve ser destacado e que auxilia no entendimento do grande número de notícias e pequeno de reportagens é o fato de que os correspondentes no Brasil, dos veículos estrangeiros, escrevem sobre as temáticas relacionadas à Amazônia sem ir à Amazônia. Tais profissionais residem principalmente na região Sudeste do Brasil. "A chamada 'grande imprensa' do país é constituída quase que exclusivamente por veículos situados no eixo Rio - São Paulo" (DALMOLIN; SILVEIRA, 2016, p. 32).

\section{Anos de maior repercussão}

$\mathrm{Na}$ Figura 2 observa-se o desenvolvimento das matérias jornalísticas, nas mídias internacional e nacional, no período de 2005 a 2017. Percebe-se que a atenção da imprensa não se desenvolveu de forma linear, pois, a partir $\mathrm{da}$ metade de 2009, houve um crescimento da produção de conteúdo pela imprensa dentro e fora do Brasil. Os anos de 2010, 2011 e 2012 foram os de maiores publicações para ambas as categorias.

Ainda de acordo com a Figura 2, na imprensa internacional, em 2010, iniciou o crescimento de publicações, em que se registrou o maior número de matérias sobre a UHE de Belo Monte, decaindo a partir de 2011 e voltando a crescer em 2016. Segundo Fleury e Almeida (2013), de 2009 a 2010, as controvérsias sobre Belo Monte tornaram-se intensas. Em $1^{\circ}$ de fevereiro de 2010, o Ibama concedeu a Licença Prévia (LP) que permitiu ao governo preparar o leilão da usina. Dentre 
as matérias primárias, destacam-se: Brasil dá luz verde à terceira maior barragem do mundo (Le Monde, 02/02/2010); Brasil, depois de longa bataIha, aprova barragem na Amazônia (The Hindu,
08/03/2010); Polêmica construção de barragem de Belo Monte no Brasil (The Guardian 02/02/2010); Brasil aprova violenta represa na floresta amazônica (The Sunday Times, 02/02/2010).

Figura 2: Número de matérias jornalísticas sobre Belo Monte no período de 2015 a 2017 em mídias internacionais e nacionais.

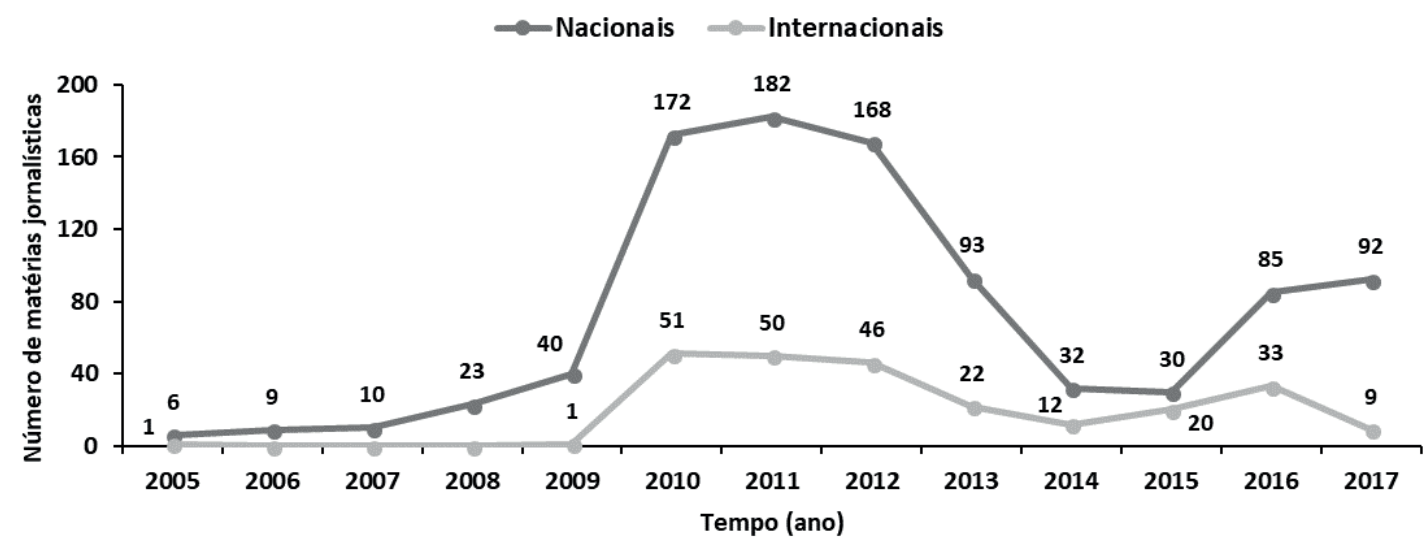

Fonte: Pesquisa de campo.

Em abril de 2010, ao ser realizado o "leilão de concessão da usina, concluído em 10 minutos, entre liminares que suspendiam sua validade e a cassação dessas liminares" (FLEURY; ALMEIDA, 2013, p. 146), os jornais noticiaram em matérias primárias: Brasil autorizou o trabalho de uma barragem controversa (La Nación, 21/04/2010); A Amazônia terá a terceira maior barragem do mundo (El País 20/04/2010); Protestantes resistem. Brasil prepara-se para construir uma barragem (The New York Times, 15/08/2010); No Brasil, os índios conhecem os futuros construtores da gigante barragem de Belo Monte (Le Monde, 23/04/2010);
Lula: Construiremos a usina hidrelétrica de Belo Monte com ou sem empresas privadas (El Mundo, 12/04/2010); Brasil / barragem: concurso suspenso (Le Figaro, 20/04/2010).

Nos meses seguintes de 2010, a UHE de Belo Monte continuou a ser noticiada pelo viés de celebridades que se diziam lutar pelo impedimento da barragem. O diretor e a atriz hollywoodianos James Cameron e Sigourney Weaver estiveram no Brasil e participaram de uma passeata em Brasília. "Associaram a construção da usina ao roteiro do filme de maior bilheteria da história do cinema, 
'Avatar'” (FLEURY; AlMEIDA, 2013, p. 147). O jornal The Guardian publicou, em 18/04/2010, que O diretor de Avatar, James Cameron, junta-se à luta de tribos amazônicas para parar a gigante barragem; James Cameron, Diretor de Avatar, protesta contra a usina de Belo Monte (The Sunday Times, 14/04/2010).

Assim como o cantor inglês Sting deu visibilidade mundial à devastação da floresta amazônica ao visitar a região em 1989, James Cameron repetiu o feito com a UHE de Belo Monte. Sobre a exposição pública de celebridades internacionais envolvidas com as questões da Amazônia, Wainberg (2016) reforça que o que as estrelas de Hollywood dizem sempre terá repercussão, pois o entretenimento norte-americano é mais poderoso do que o de qualquer outro país. Para Jampolsky (2012), o envolvimento de celebridades em causas como esta é assunto controverso, por mais se parecer um evento midiático do que pela proteção das pessoas e dos recursos naturais da Amazônia.

Das 16 matérias publicadas no restante do ano de 2010 , as primárias reforçaram os malefícios da construção da barragem, os protestos pelo Brasil, a ocupação no local da barragem, enquanto as secundárias apresentaram um tom mais crítico sobre a construção da barragem. No oposto em relação aos demais meios está o jornal chinês Pleople's Daily, que apresentou matéria com destaque positivo aos investimentos do governo em Belo Monte. A matéria teve no título: Lula defende desenvolvimento sustentável na região da floresta amazônica (15/10/2010).

Em 25 de novembro de 2010, o jornal alemão Die Zeit noticiou as formas de investimentos dos chineses em barragens, com a matéria Exemplos de Barragens - As empresas de construção chinesas são líderes. Belo Monte é uma das hidrelétricas citadas. Na matéria, a jornalista alemã Waltina Scheumann escreveu: "Representantes da indústria de construção alemã atribuem os altos investimentos chineses em barragens a distorções de concorrência, que também se originam do fato de que as empresas alemãs estão comprometidas com os padrões ambientais, e as chinesas não". A matéria ainda denuncia que as empresas chinesas calculam baixos custos trabalhistas para lucrarem e se beneficiam da taxa de câmbio fixa, por isso investem em usinas pelo mundo.

No decorrer dos anos, nota-se, na cobertura do People's Daily, a proximidade entre o governo da China e do Brasil. As publicações não fazem críticas à UHE de Belo Monte; pelo contrário, elas abordam as visitas do presidente chinês ao Brasil e os acordos de cooperação em investimentos nas linhas de energia brasileiras, entre elas Belo Monte. Vieira 
e colaboradores (2016) apontam que entre Brasil e China há uma relação de dependência: o Brasil tem recursos naturais em abundância; em contrapartida, precisa de investimentos econômicos para crescer no cenário mundial. Por outro lado, a China é uma das maiores potências econômicas, mas já explorou o que pôde dos próprios recursos naturais a ponto de esgotá-los.

\section{0 auge de Belo Monte na pauta nacional}

Em 2011, o jornalismo internacional produziu uma única matéria a menos em relação ao ano anterior, enquanto isso o jornalismo nacional mostrou o maior índice de divulgação dos 12 anos, com 182 matérias, sendo 122 primárias e 60 secundárias. $\mathrm{O}$ ano foi marcado na imprensa estrangeira pelas dificuldades do consórcio Norte Energia em cumprir as condicionantes referentes às mitigações de impactos ambientais da Licença Prévia e, consequentemente, sem a possibilidade de receber a Licença de Instalação (LI) nº 770/2011, que autorizaria o início das obras.

Sequeira (2015) conta que, em 2011, o governo brasileiro por meio do presidente do Ibama, na época, Américo Ribeiro Tunes, concedeu uma espécie de "licença parcial". A partir daí, Oliveira e Cohn (2014) relatam que a Norte Energia pôde construir alojamentos, canteiros industriais, áreas de estoque de solo e madeiras. A imprensa estrangeira noticiou: Começa trabalho de construção da barragem hidrelétrica de Belo Monte (The Guardian, 10/03/2011); Começam obras de gigantesca hidrelétrica na Amazônia (El Espectador, 07/03/2011); Após longa batalha, Brasil aprova barragem na Amazônia (The Hindu, 03/06/2011); Luz verde para a construção de uma gigante barragem na Amazônia (Le Monde, 01/06/2011).

Em abril de 2011, a Comissão Interamericana de Direitos Humanos (CIDH), órgão vinculado à Organização dos Estados Americanos (OEA), enviou um documento ao governo brasileiro para pedir a suspensão imediata do processo de licenciamento da usina (sAntos et al., 2012). Esse fato também foi notícia estrangeira, com as manchetes: Novo desafio de direitos humanos para a barragem de Belo Monte no Brasil (The Guardian, 12/04/2011); Brasil rejeita solicitação do painel para parar a barragem (The New York Times, 05/04/2011); Brasil e OEA enfrentam a usina hidrelétrica de Belo Monte (El País, 06/04/2011).

Em outubro de 2011, indígenas e líderes sociais ocuparam o maior canteiro de obras da usina, o Sítio Belo Monte. Manifestantes ocupam o local de construção da usina hidrelétrica (Süddeutsche Zeitung, 28/10/2011); No Brasil, a ira de indios e ecologistas contra a barragem de Belo Monte (Le Monde, 29/10/2011). 
Ainda em 2011, observou-se que o jornal Folha de São Paulo reforçou o poder do governo nacional e de órgãos internacionais sobre a efetivação da barragem: Dilma volta a defender a construção de hidrelétricas (05/07/2011); Brasil é um país soberano, diz ministro sobre Belo Monte (25/10/2011); Presidente da Light confirma interesse em usina Belo Monte (05/10/2011); Norte Energia aprova parceiros de Belo Monte nesta terça-feira (24/10/2011); Cemig e Light compram participação em Belo Monte (26/10/2011); Mercedes-Benz fornecerá 540 caminhões para Belo Monte (11/08/2011).

Na análise das matérias da Folha de São Paulo, percebe-se, pelo título, a tentativa de atribuir um caráter de agressividade aos indígenas, a partir dos atos de protesto pela reivindicação do usufruto das próprias terras: Movimento social ameaça (grifo nosso) empresas interessadas em Belo Monte (23/03/2011); Índio prevê briga e morte (grifo nosso) se governo prosseguir com Belo Monte (08/02/2011). Vieira (2015) é enfático ao descrever as marcas da cultura hegemônica impostas pela colonização, que se estendem até hoje, inclusive dentro da imprensa. "O índio é apresentado como sendo o transtorno, o baderneiro, a sujeira, o estranho e o impuro da cidade. É aquele que sempre traz algum tipo de desordem, dúvida e incerteza aos que dominam e controlam o poder" (VIEIRA, 2015, p. 175).

\section{Queda nas publicações}

Em 2012, a insatisfação dos trabalhadores da UHE de Belo Monte, com os baixos salários, e dos indígenas, com a construção da barragem, ocasionou a paralisação das atividades e a ocupação dos canteiros de obras. A Justiça, mais uma vez, determinou a parada das obras por irregularidades. Os sites jornalísticos internacionais publicaram 28 matérias primárias, sendo 12 sobre os protestos de trabalhadores e indígenas. O Jornal de Notícias, de Portugal, publicou em 26 de junho de 2012: Protesto paralisa parte da obra da barragem de Belo Monte.

As demais matérias (16) trataram das autorizações e suspensões das obras da hidrelétrica. Foram publicadas na imprensa internacional: A Justiça brasileira ordena parar os trabalhos da controversa hidrelétrica na Amazônia (El País, 14/08/2012); Brasil: justiça permite que a construção da barragem retome (The New York Times, 28/08/2012); Construção da barragem de Belo Monte interrompida pelo tribunal brasileiro (The Guardian, 16/08/2012).

Já no jornal Folha de São Paulo, das 104 matérias jornalísticas primárias publicadas em 2012, 66 trataram dos atos de protestos, com maior destaque dos indígenas e dos movimentos sociais. Dez delas abordaram os impasses na Justiça sobre a continuidade das obras. O restante focou em questões de financiamento de 
Belo Monte, aumento de consumo de energia no país, entre outras.

\section{Inauguração é abafada por corrupção}

O ano de 2016 foi outro ponto alto na divulgação. Nele, elevou-se mais uma vez a divulgação por parte dos jornais internacionais e nacionais. $\mathrm{O}$ ano foi marcado pelo início da operação comercial da usina. Porém, para os sites estrangeiros, isso foi praticamente insignificante se comparado com as delações na Justiça brasileira sobre esquemas de propina envolvendo políticos e as empreiteiras de Belo Monte. Do total de 33 matérias, apenas uma tratou do início da operação; o restante delas, principalmente as secundárias, trouxeram Belo Monte como referência aos esquemas de corrupção, tais como: Corrupção: A confissão de um senador sobre Dilma e Lula da Silva afeta o Brasil (Clarín, 16/03/2016); Suborno usado em doações legais para campanha de Dilma (Jornal de Notícias, 07/04/2016).

Das 85 matérias jornalísticas publicadas pelos jornais Folha de São Paulo e O Globo, em 2016, 57 foram primárias. A prioridade de ambos os jornais foi a divulgação da liberação de recursos, por empresas privadas e governo, para mais investimento em Belo Monte, início das operações e cobrança das mitigações ambientais. Registraram-se apenas nove matérias primárias sobre investigações de falsos contratos com Belo Monte e esquemas de propina.
Das 28 notícias secundárias, 10 foram do jornal Folha de São Paulo e 18 de O Globo. Ambos os jornais trataram cautelosamente dos assuntos referentes à corrupção. A exemplo, temos: Andrade Gutierrez divulga pedido de desculpas por ilegalidades em obras (Folha de São Paulo, 08/05/2016); Andrade Gutierrez encarava propina como 'custo comercial' das obras (O Globo, 28/07/2016).

No último ano de coleta da amostragem, o jornalismo nacional elevou novamente o número de publicações para 92 matérias jornalísticas, sete a mais do que no ano anterior. O diferencial desse ano foi que os jornais nacionais dobraram o número de publicações secundárias e apresentaram um número reduzido de matérias jornalísticas em que Belo Monte foi a temática principal. Das 92 publicações, 28 foram primárias e 64 secundárias. As primárias abordaram autorização para operação de turbinas, liberação de recursos de empresas privadas para continuidade de Belo Monte, Ibama e Força de Segurança Nacional em proteção à Hidrelétrica. Já as secundárias abordaram os esquemas de delações de políticos e empresários envolvendo a UHE Belo Monte. Temáticas como: "exploração sexual ribeirinha", "privatização da Eletrobrás" e "baixo nível de água nas hidrelétricas" também foram trabalhadas.

Ainda em 2017, percebeu-se uma queda 73\% nas publicações internacionais. Nesse ano, 
houve o registro de apenas duas matérias primárias e sete secundárias. As primárias abordaram o desfile da Escola de Samba da Imperatriz Leopoldinense, que, no Carnaval desse ano, homenageou os povos indígenas do Xingu ao trazerem a temática das ameaças contra o meio ambiente geradas pelos empresários do agronegócio. As sete notícias secundárias versaram sobre o "acordo de energia entre China e Brasil" e "por que os latino-americanos são obcecados por barragens".

\section{5 a 2009: período de inexpressiva atenção midiática}

Em relação aos anos com menores registros de matérias jornalísticas (Figura II), verifica-se que, de 2005 até 2009, Belo Monte foi praticamente invisível na imprensa estrangeira. Nesse período há o registro de apenas duas notícias, uma delas publicada em 20 de novembro de 2005, no The New York Times, com a chamada Brasil avalia custos e benefícios da aliança com a China. O jornal destacou a pressão do governo brasileiro em construir a barragem, o apoio do governo chinês para a obra e a desaprovação dos indígenas, que não se viam beneficiados com o empreendimento.

Em 2005 o jornal Folha de São Paulo publicou seis matérias sobre Belo Monte, duas primárias e quatro secundárias. Apenas uma notícia abordou a autorização do Congresso Nacional para a implantação de Belo Monte. A manchete dizia: Congresso autoriza governo a estudar hidrelétrica no Rio Xingu.

Em 2006, o jornal Folha de São Paulo noticiou sobre a possibilidade de construção da hidrelétrica, porém tendo-a como informação secundária em nove matérias. Foram oito notícias com as seguintes abordagens: os riscos de apagão no Brasil, os investimentos no setor de energia do Brasil, incentivo do governo do Presidente Lula à construção de Belo Monte e uma reportagem sobre racionamento de luz elétrica. Nota-se, pela chamada das matérias, um certo "terror" imposto pelo jornal ao relacionar um blecaute geral no Brasil com a ausência de investimentos e a ampliação do parque fornecedor de energia. Sousa (2016, p. 61) reforça o poder que a mídia exerce sobre a mente do público - inclusive ao gerar sentimentos como medo ao "exercer uma espécie de controle, ou até mesmo de governo, sobre nós, (...) nos coagindo, amedrontando-nos, diante da possibilidade de sermos vitimados".

Em 2008, foram 23 matérias publicadas no decorrer do ano no jornal Folha de São Paulo. Nesse ano, o destaque deu-se à suspeita de agressão ou ato de defesa dos indígenas contra um dos funcionários da Eletrobrás. A Justiça apurou o fato, porém as manchetes do jornal Folha de São Paulo davam a sentença 
final: Presidente da FUNAI critica ataque de índios (grifo nosso) a engenheiro da Eletrobrás no Pará (Folha de São Paulo, 21/05/2008); PF intima padre para depor sobre agressão contra (grifo nosso) engenheiro da Eletrobrás (Folha de São Paulo, 02/05/2008); Engenheiro é agredido (grifo nosso) em encontro sobre Xingu, diz Eletrobrás (Folha de São Paulo, 20/05/2008); Contra usina, indios ferem (grifo nosso) engenheiro em Altamira (Folha de São Paulo, 21/05/2008). A imprensa nacional também priorizou divulgar os investimentos internacionais a favor de Belo Monte. A notícia publicada em 11 de julho de 2008 , no jornal Folha de São Paulo, trouxe no título
Chineses querem investir mais em projetos do PAC. Nela, Belo Monte é a aposta dos investimentos chineses.

Em 2009 ocorreu mais um salto positivo nas notícias primárias, especialmente no jornal Folha de São Paulo. Das 40 notícias, 31 foram primárias. O ano foi marcado pela entrega, por parte da Eletrobrás, dos estudos de viabilidade de Belo Monte, suspensão do licenciamento da hidrelétrica por parte da Justiça Federal, derrubada da liminar que desconsiderava o licenciamento ambiental de Belo Monte e suspensão do leilão da usina.

Figura 3: Número de matérias primárias e secundárias sobre a UHE de Belo Monte entre o período de 2015 a 2017, por país.

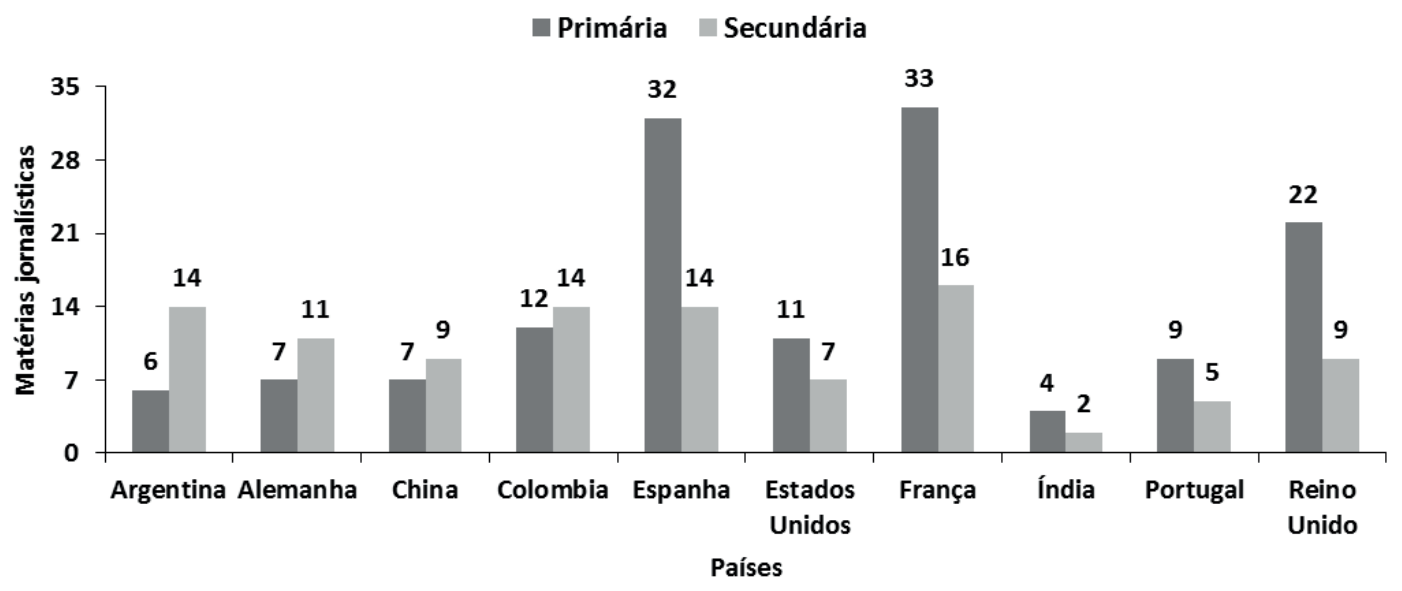

Fonte: Pesquisa de campo.

\section{Belo Monte na mídia europeia}

Na Figura 3 observa-se França, Espanha e Reino Unido como os países que mais noticiaram a UHE de Belo Monte. Na história do Brasil e da Amazônia, os países europeus em destaque têm participação nos processos 
de colonização e no discurso estrangeiro que se solidificou sobre a região amazônica ao logo dos séculos. Além disso, França, Espanha e Reino Unido apresentam os jornais de maior influência no mundo.

Jean-Pierre Langellier, jornalista do Le Monde desde 1976, correspondente no Brasil, conta que, entre os países da América Latina, os franceses têm o maior interesse nas terras brasileiras. "O país, de fato, vem se aproximando da França, com ações como o ano do Brasil na França, em 2005, e o ano da França no Brasil, em 2009"' (BENICIO, 2014, p. 6).

O jornalista paraense Lúcio Flávio Pinto é enfático ao escrever que "antes de sermos nacionais já éramos internacionais. A internacionalização é uma característica na Amazônia, mais forte do que em qualquer outra região brasileira" (PINTO, 2014, p.14). Como terra "descoberta", vem historicamente sendo contada por relatos estrangeiros e não pelos que habitam nela. Em um artigo sobre a internacionalização da Amazônia, Lúcio Flávio Pinto diz que a Amazônia faz parte do mundo como um produto exótico (PINTO, 1992).

De acordo com Pratt (1999), os discursos estrangeiros muitas vezes são as fontes da nossa identidade nacional. Ferraz (2002) justifica que o Brasil passou a ser conhecido na Europa a partir dos relatos dos viajantes estrangeiros em cartazes de jesuítas portugueses. Herman e McChesney (1998) atribuem aos meios de comunicação global o título de missionários do capitalismo corporativo. "Nesse contexto, as matérias dos correspondentes internacionais atuam como os novos 'relatos de viagem', levando as notícias do Brasil para os públicos estrangeiros" (PAGANOTTI, 2007).

Paganotti (2007) pesquisou os estereótipos do Brasil existentes nas coberturas jornalísticas realizadas pelos correspondentes internacionais do The New York Times (EUA), El Mundo (Espanha), Diário de Notícias (Portugal), The Guardian e The Observer (Inglaterra). Ele constatou que, quando a pauta jornalística envolve a Amazônia, cria-se a imagem de Brasil Verde. "Nos jornais, é predominantemente representada (a Amazônia) de modo negativo por meio da depredação ambiental e dos menos frequentes estereótipos sobre a falta de soberania na Amazônia, uma 'terra sem lei' vista como 'celeiro' para o agronegócio" (PAGANOTTI, 2007, p.10).

Na Figura 4, apresenta-se a proporção de matérias primárias e secundárias conforme os jornais. Nota-se que Le Monde (França), The Guardian (Reino Unido) e El País (Espanha) foram os que alcançaram maior número de matérias primárias sobre a Hidrelétrica 


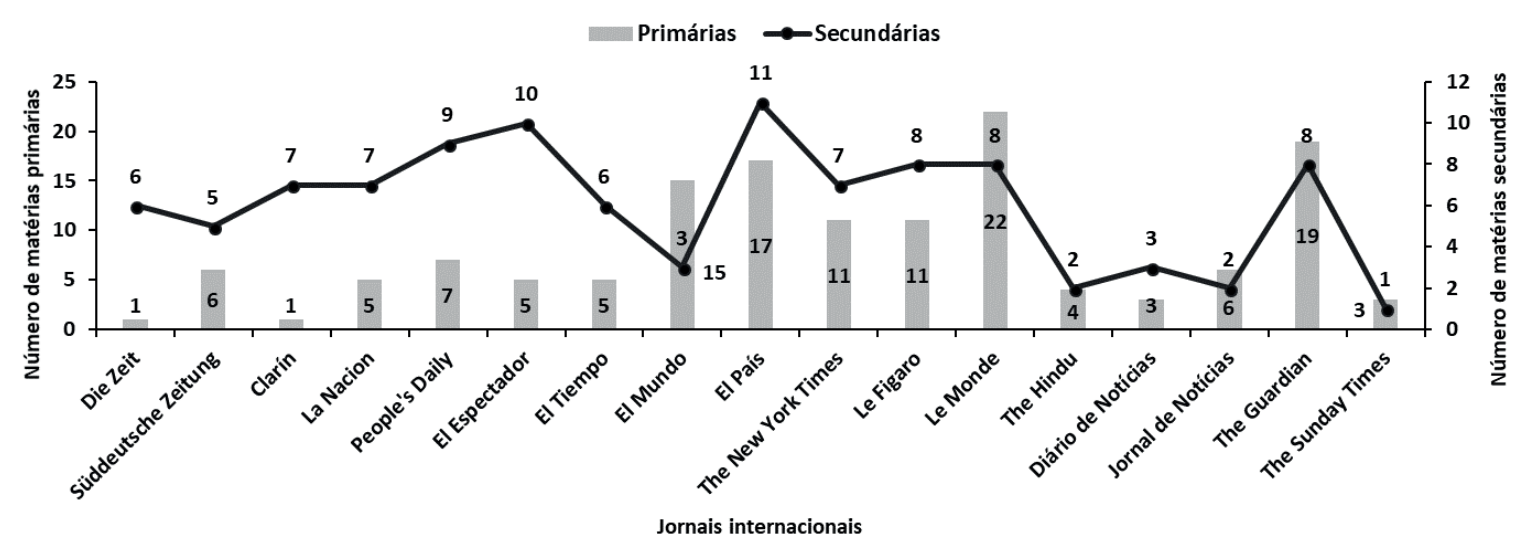

Fonte: Pesquisa de campo.

The Guardian é considerado "o melhor jornal eletrônico do mundo" (MOLINA, 2007, p. 370); fundado em 1821, na Inglaterra, o jornal mantém correspondentes na América Latina desde 1990. Segundo a pesquisadora de mídia internacional, Dalpiaz (2013), o olhar britânico enxerga no Brasil uma nação emergente e, ao mesmo tempo, cheia de problemas. Já o El País é o jornal mais conhecido e influente da Espanha; em 2013, lançou uma versão em português devido ao grande acesso dos brasileiros.

Não houve nenhuma ocorrência de notícias no jornal chinês Yangtse Evening New's, nos jornais coreanos The Dong A Ilbo e The Joongang
Ilbo, nem no jornal dos Estados Unidos, The Wall Street Journal.

\section{Conclusão}

A une de Belo Monte, localizada na Amazônia brasileira, é a terceira maior hidrelétrica do mundo. Porém, mais de $90 \%$ de todo conteúdo jornalístico produzido sobre ela é constituído de informações compactas e menos exploradas, chegando a ser quase inexpressivo os números de reportagens aprofundadas sobre essa UHE.

Percebe-se que a visão histórica internacional dos países sobre a Amazônia oportunizou mobilização em escala mundial para noticiar 
Belo Monte, a ponto de surgirem especulações na imprensa internacional sobre o futuro da floresta, dos rios e dos povos que habitam aquela região da Amazônia. Impera a ideia estrangeira de uma Amazônia que é de interesse mundial.

Os índios foram tirados das próprias terras e das relações que construíram com a natureza, foram reportados pela imprensa nacional como baderneiros, causadores da desordem, intrusos nos próprios territórios ao reivindicarem as terras que são suas por direito. Surpreendentemente negativa foi à função dos jornais brasileiros ao enfatizarem Belo Monte como proposta de crescimento econômico e solução para os problemas de energia no país. A produção de um número maior de conteúdo não assegurou a divulgação real da identidade desses personagens, ao contrário da imprensa internacional, que atuou como conscientizadora das problemáticas socioambientais da hidrelétrica, o que pode ser positivo mundialmente.

\section{Referências}

ADGHIRNI, Zélia Leal. O jornalista: do mito ao mercado. Estudos em Jornalismo

e Mídia, v. 2, n. 1, p. 45-57, 2005. Disponível em: < http://www.repositorio.unb.br/ bitstream/10482/12442/1/ARTIGO_ JornalismoMitoMercado.pdf $>$. Acesso em: 14 jun. 2016.
AGUIAR, Leonel Azevedo; RODRIGUES, Claudia. Ser jornalista na contemporaneidade: uma contribuição aos estudos da profissão.

Revista Brasileira de Ensino de Jornalismo, v. 7, n. 21, 2017. Disponível em:<http://www. fnpj.org.br/rebej/ojs/index.php/rebej/article/ viewFile/491/321>. Acesso em: 28 jan. 2018.

ASSOCIAÇÃO NACIONAL DE JORNAIS (ANJ). Maiores jornais do Brasil. 2011. Disponível em: <http://www.anj.org.br/os-100-maioresjornais-do-mundo-2/>. Acesso em: 11 nov. 2017.

\section{BARBOSA, Rui. A imprensa e o dever da} verdade. São Paulo: Editora Montecristo, 1990. 53 p. Disponível em: < http://www. casaruibarbosa.gov.br/dados/DOC/artigos/ rui_barbosa/FCRB_RuiBarbosa_AImprensa_e o_dever_da_verdade.pdf $>$. Acesso em: 12 dez. 2017.

BARDIN, L. Análise de Conteúdo. São Paulo: Edições 70, 2011.

BENICIO, Milla. Do Brasil no Le Monde. Revista Garrafa, v. 33, p.1-9, 2014. Disponível em: http://www.letras.ufrj.br/ciencialit/ garrafa/garrafa33/Milla_Benicio_Da_ possibilidade_traduzir_cultura_Garrafa_33. pdf. Acesso em: 15 mar. 2018.

BERMANN, Célio. O projeto da Usina Hidrelétrica Belo Monte: a autocracia energética como paradigma. Novos Cadernos NAEA, v. 15, n. 1, p. 5-23, 2012. Disponível em: <https://periodicos.ufpa.br/index.php/ ncn/article/view/895/1343>. Acesso em: 10 maio 2018.

BRASIL, República Federativa. Diário da Câmara dos Deputados. Brasília. Congresso, 2005. 
COSTA, Alda Cristina.; OLIVEIRA, Ivana Cláudia; RAVENA, Nírvia. Vozes institucionais e os discursos de dominação: análise dos grandes projetos hidrelétricos na Amazônia.

\section{Revista FAMECOS: mídia, cultura e} tecnologia, v. 24, n. 2, 2017. Disponível em:< http://www.redalyc.org/pdf/4955/495553931001. pdf > . Acesso em: 11 jul. 2018.

DALMOLIN, Aline Roes; SILVEIRA, Ada Cristina Machado Um abismo vigiado: segurança e soberania no discurso jornalístico televisual sobre fronteiras na Amazônia.

\section{Revista Internacional de Ciencias Sociales,} v. 5, n. 1, p. 29-41, 2016. Disponível em:< http://journals.epistemopolis.org/index.php/ csociales/article/view/368/27>. Acesso em 11 jun. 2018.

DALPIAZ, Jamile. G. Representações do Brasil na imprensa britânica: uma análise cultural do jornal The Guardian. $2013.203 \mathrm{f}$. Tese (Doutorado em Comunicação Social) Pontífice Universidade Católica do Rio Grande do Sul, Porto Alegre.

\section{EMPRESA DE PESQUISA ENERGÉTICA.} Plano Nacional de Expansão de Energia 20112020. Brasília: Ministério de Minas e Energia; Empresa de Pesquisa Energética, 2011. 344p.

FEARNSIDE, Philip. Gases de efeito estufa no EIA-RIMA da hidrelétrica de Belo Monte.

Novos Cadernos NAEA, v. 14, n. 1, 2011. Disponível em: < https://periodicos.ufpa.br/ index.php/ncn/article/view/596/848 > . Acesso em: 23 maio 2017.

FERRARI, Pollyana. São Paulo: Contexto, 2014. $128 \mathrm{p}$.

FERRAZ, Oséias Silas. "Nota Preliminar". In: CAMINHA, Pero Vaz de. Carta ao rei Dom Manuel. Belo Horizonte: Crisálida, 2002.
FERREIRA, Antônia M.M; SALATI, Enéas. Forças de transformação do ecossistema amazônico. Estudos Avançados, v. 19, n. 54, p. 25-44, 2005. Disponível em: <http://www. scielo.br/pdf/ea/v19n54/o2.pdf>. Acesso em: 12 jun. 2018.

FERREIRA, Norma S.A. As pesquisas denominas "estado da arte". Educação e Sociedade, v, 23, n. 79, p. 257-272, 2002. Disponível em: <http://www.scielo.br/pdf/es/ v23n79/10857.pdf>. Acesso em: 15 fev. 2017.

FLEURY, Lorena Candido; ALMEIDA, Jalcione. A construção da Usina Hidrelétrica de Belo Monte: conflito ambiental e o dilema do desenvolvimento. Ambiente \& Sociedade, v. 16, n. 4, p. 141-158, 2013. Disponível em: <http:// www.redalyc.org/pdf/317/31729904009.pdf>. Acesso em 12 fev. 2018.

FONSECA, André Azevedo da. Água de uma fonte só. In VILLAS BOAS, Sérgio (org.). Formação e Informação ambiental: jornalismo para iniciados e leigos. SP: Summus, 2004.

HERMAN, Edward S..; MCCHESNEY, Robert Waterman. "The rise of global media". In: The global media - the new missionaries of corporate capitalism. Nova Déli: Madhyam Books, 1998.

JAMPOLSKY, Jacquelyn Amour. Activism is the New Black-Demonstrating the Benefits of International Celebrity Activism through James Cameron's Campaign against the Belo Monte Dam. Colo. J. Int'l Envtl. L. \& Pol'y, v. 23, p. 227, 2012. Disponível em: < https://heinonline.org/ HOL/LandingPage?handle=hein.journals/ colenvlp23\&div=9\&id=\&page $=>$. Acesso em: 10 jul. 2018. 
JUNK, W.J.; MELLO, J.A.S.N. Ecological impacts of hydroelectric dams in Brazilian Amazon Basin. Estudos Avançados, v. 4, n.8, p.126-143. 1990.

\section{KISCHINHEVSKY, Marcelo. Convergência}

das redações: Mapeando os impactos do novo cenário midiático sobre o fazer jornalismo. In: RODRIGUES, Carla. Jornalismo on-line: Modos de fazer. Rio de Janeiro: Ed. PUC-Rio; Porto Alegre: Sulina, 2009.

LIMA, Maria Thereza da Silva Lopes et al. On the Brazilian energetic situation 1970-2030. Ciência e Natura, v. 37, p. 0616, 2015.Disponível em:<https://periodicos. ufsm.br/index.php/cienciaenatura/article/ viewFile/18492/pdf>. Acesso em: 14 dez.2018.

LOUREIRO, Violeta Refkalefsky. Amazônia: uma história de perdas e danos, um futuro a (re) construir. Estudos Avançados, v. 16, n. 45, p. 107-121, 2002. Disponível em: < http://www. scielo.br/pdf/ea/v16n45/v16n45a08.pdf >. Acesso em: 1 jun. 2018.

MACIEL, Harine Matos; KHAN, Ahmad Saeed. Intensidade energética dos países integrantes do BRICS (Brasil, Rússia, Índia, China e África do Sul). Revista Brasileira de Gestão Ambiental e Sustentabilidade, v. 4, n. 8, p. 443459, 2017. Disponível em:<<http://revista. ecogestaobrasil.net/v4n8/v04no8a16a.html>. Acesso em 12 jun. 2018.

MAFFESOLI, Michel. A comunicação sem fim (teoria pós-moderna da comunicação). Revista FAMECOS, Porto Alegre, n.20, p.13-20. 2003.

MAGNONI, Antônio Francisco; MIRANDA, Giovani Vieira. Os meandros de uma comunicação (hiper) local em um cenário rural. Pauta Geral-Estudos em Jornalismo, v. 3, n. 1, p. 91-110, 2016. Disponível em: <http://177.101.17.124/index.php/pauta/article/ view/8696/5125>. Acesso em 26 jun. 2018.

MENDES, Carlos A. N. Consumo de energia e crescimento econômico: uma relação em estudo com foco nos países componentes do BRICS. Santa Maria, 2014. Originalmente apresentada como dissertação de mestrado, Universidade Federal de Santa Maria, 2014. MOLINA, Matías M. Os melhores jornais do mundo. Uma visão da imprensa internacional. São Paulo: Globo, 2007. 680 p.

MORETTO, Evandro Mateus et al. Histórico, tendências e perspectivas no planejamento espacial de usinas hidrelétricas brasileiras: a antiga e atual fronteira Amazônica.

Ambiente \& Sociedade, v. 15, n. 3, p. 141-164, 2012. Disponível em: < http://www.scielo.br/ pdf/asoc/v15n3/a09v15n3.pdf >. Acesso em: 5 jan. 2018.

MORETZSOHN, Sylvia Debossa. O "novo ritmo da redação" de O Globo: a prioridade ao jornalismo digital e seus reflexos nas condições de trabalho e produção da notícia. Parágrafo, v. 2, n. 2, p. 59-79, 2014. Disponível em: $<$ http://www.revistaseletronicas. fiamfaam.br/index.php/recicofi/article/ view/234/280>. Acesso em: 24 jan.2018.

NEVEU, Erik. As notícias sem jornalista: uma ameaça real ou uma história de terror. Brazilian Journalism Research, v. 6, n. 1, p. 2957, 2010. Disponível em:< https://bjr.sbpjor. org.br/bjr/article/view/246/244>. Acesso em: 4 jun. 2018.

NEVEU, Erik. Sociologia do jornalismo. São Paulo: Loyola, 2006. 216 p. 
OLIVEIRA, João Pacheco de; COHN, Clarice. (Org). In Belo Monte e a Questão

Indígena. Brasília-DF: ABA, 2014.

PAGANOTTI, Ivan. Imagens e estereótipos do Brasil em reportagens de correspondentes internacionais. Rumores, v. 1, n. 1, 2007. Disponível em: <http://www.journals.usp.br/ Rumores/article/view/51102/55172>. Acesso em: 13 mar. 2018.

PINTO, Lúcio Flávio Amazônia: uma página ainda escrita em garranchos. Revista Sentidos da Cultura, v. 1, n.1, p. 11-16, 2014. Disponível em: < https://paginas.uepa.br/seer/index.php/ sentidos/article/view/348/325>. Acesso em: 16 abr. 2018.

PINTO, Lúcio Flávio. A internacionalização da Amazônia. Revista USP, n. 13, p. 10-14, 1992. Disponível em: < https://www.revistas.usp.br/ revusp/article/viewFile/25592/27334 >. Acesso em: 11 jul. 2018.

PRATT, Mary Louise. Os olhos do império: relatos de viagem e transculturação. Bauru: Edusc, 1999. 394 p.

SANTOS, Thauan. et al. Belo Monte: Impactos sociais, ambientais, econômicos e políticos.

Tendências, v. 13, n. 2, p. 214-227, 2012.

Disponível em: $<$ https://dialnet.unirioja.es/ servlet/articulo? codigo $=4241061>$. Acesso em: 17 mar.2018.

SEQUEIRA, João Elbio; SILVA, Maria Dolores.O ativismo judicial transnacional e a "Transnational Advocacy Network" na construção da Usina Hidrelétrica de Belo Monte. Revista Política Hoje-ISSN: 01047094, v. 23, n. 2, p. 177-202, 2015. Disponível em: <https://periodicos.ufpe.br/revistas/ politicahoje/article/view/3747/3049>. Acesso em 29 maio 2018.
SEVA FILHO, Oswaldo. Hidrelétricas na

Amazônia e no Xingu. Uma síntese dos problemas para as populações e a natureza. Livros, p. 57-66, 2015. Disponível em: < http:// www.abep.org.br/publicacoes/index.php/ livros/article/viewFile/131/128 > . Acesso em: 13 fev. 2018.

SILVA, Fernando Firmino. Jornalismo reconfigurado: tecnologias móveis e conexões sem fio na reportagem de campo. In: XXXI Congresso Brasileiro de Estudos Interdisciplinares da Comunicação, Natal, 2008. Anais...

VIEIRA, Carlos Magno Naglis. O que dizem as crianças não indígenas sobre as populações indígenas: um estudo a partir de desenhos infantis. Tellus, n. 28, p. 167-176, 2015.

Disponível em: <http://tellus.ucdb.br/projetos/ tellus/index.php/tellus/article/view/359/340>. Acesso em 10 jun. 2018.

VIEIRA, Pedro Abel; BUAINAIN, Antônio Marcio; COVOLAN, Eliana Valeria Covolan O Brasil alimentará a China ou a China engolirá o Brasil?. Revista Tempo du Mundo, IPEA, v. 2, n. 1, p. 51-82, 2016. Disponível em: <http://repositorio.ipea. gov.br/bitstream/11058/6440/1/TdM_v2_ n1.pdf\#page=53>. Acesso em: 11 jun. 2018.

WAINBERG, Jacques Alkalai. O ativismo das estrelas e a comunicação dissidente.

Animus (Santa Maria. Online), v. 15, n.19, 2016. Disponível em: <http://meriva.pucrs.br/ dspace/bitstream/10923/9847/2/O_ativismo_ das_estrelas_e_a_comunicacao_dissidente. pdf>. Acesso em: 11 jun. 2018.

XINGU VIVO. Cronologia de Belo Monte. Xingu Vivo. [S.d.]. Disponível em: http://www. 
xinguvivo.org.br/x23/?page_id=3012 Acesso

em: 5 set. 2015 .

ZAGO, Gabriela Da Silva; BASTOS, Marco

Toledo. Visibilidade de Notícias no Twitter e no

Facebook: Análise Comparativa das Notícias

mais Repercutidas na Europa e nas Américas.

Brazilian Journalism Research (Online), v. 9,

p. 116 - 133, 2013. Disponível em:< https://bjr.

sbpjor.org.br/bjr/article/view/510/445>. Acesso

em: 1 maio 2018. 


\section{Belo Monte: the international and national visibility of the Hydroelectric Plant in the main newspapers of the American, European and Asian continente}

\begin{abstract}
Newspapers are still the only sources of information about the environment. In view of this fact and the great impact of the construction of the hydroelectric power plant (UHE) of Belo Monte, the objective of the study was to carry out a survey of the journalistic matters on Belo Monte between 2005 and 2017. The data were collected on the most circulating newspaper sites on the American, European and Asian continents. The content of 1,188 materials was analyzed qualitatively and quantitatively, according to the proposal of Bardin (2011). The height of the disclosure occurred with the auction of the concession of the plant and with the spectacularization of celebrities who came to the Amazon to fight against Belo Monte. One can perceive the nternational historical view on the Amazon, as well as the idea of a world-owned Amazon.
\end{abstract}

\section{Keywords}

Framework. Content analysis. Journalism. Amazon. Belo Monte.

\section{Belo Monte: la visibilidad internacional y nacional de la central hidroeléctrica en los principales diarios del continente americano, europeo y asiático}

\author{
Resumen \\ Los periódicos siguen siendo las únicas fuentes de \\ información sobre el medio ambiente. En vista de \\ este hecho y del gran impacto de la construcción \\ de la central hidroeléctrica (UHE) de Belo Monte, \\ el objetivo del estudio fue llevar a cabo un estudio \\ de los asuntos periodísticos en Belo Monte \\ entre 2005 y 2017. Los datos se recolectaron en \\ los sitios de periódicos más circulantes de los \\ continentes americano, europeo y asiático. Se \\ analizó cualitativamente y cuantitativamente \\ el contenido de 1.188 materias, de acuerdo con \\ la propuesta de Bardin (2011). La altura de la \\ divulgación ocurrió con la subasta de la concesión \\ y con la espectacularización de celebridades \\ que vinieron al Amazonas para luchar contra \\ Belo Monte. Percibimos la visión histórica \\ internacional de la Amazonia, así como la idea \\ de una Amazonia de propiedad mundial.
}

\section{Palabras clave}

Marco. Análisis de contenido. Periodismo. Amazonas. Belo Monte.

\section{Renata da Cruz Paes}

Jornalista e mestranda do Programa de Pós-Graduação em Ciências Ambientais da Universidade do Estado do Pará. E-mail: contact.renatapaes@gmail.com ORCID: https://orcid.org/0000-0002-1230-2490

\section{Priscila Sanjuan de Medeiros Sarmento}

Doutora em Ciências Ambientais pela Universidade Federal do Pará e bolsista de pós-doutorado do Programa de PósGraduação em Ciências Ambientais da Universidade do Estado do Pará. | E-mail: priscilasanjuanbio@yahoo.com.br ORCID: https://orcid.org/0000-0002-5001-9573

\section{Altem Nascimento Pontes}

Doutor em Física pela Universidade Estadual de Campinas e coordenador do Programa de Pós-Graduação em Ciências Ambientais da Universidade do Estado do Pará. | E-mail: altempontes@hotmail.com ORCID: https://orcid.org/0000-0002-9001-4603

Concepção e desenho do estudo: Renata Paes, Priscila Sanjuan, Altem Pontes Aquisição, análise ou interpretação dos dados: Renata Paes Redação do manuscrito: Renata Paes Revisão crítica do conteúdo intelectual: Priscila Sanjuan, Altem Pontes 